\title{
Role of MAP kinase phosphatases in GnRH-dependent activation of MAP kinases
}

\author{
T Zhang and M S Roberson
}

Department of Biomedical Sciences, College of Veterinary Medicine, Cornell University, Ithaca, New York 14853, USA

(Requests for offprints should be addressed to M S Roberson; Email: msr14@cornell.edu)

\begin{abstract}
$\mathrm{GnRH}$ controls the synthesis and release of the pituitary gonadotropic hormones. MAP kinase (MAPK) cascades, including extracellular signal-regulated kinase (ERK) and c-Jun N-terminal kinase (JNK) pathways, are crucial for $\mathrm{GnRH}$-induced gene activation. In the present study, we investigated the function of GnRH-induced MAPK phosphatases (MKPs) using an in vivo mouse model as well as the $\alpha \mathrm{T} 3-1$ cell line. Following $\mathrm{GnRH}$ agonist stimulation, in vivo gene profiling demonstrated that both MKP-1 and MKP-2 are induced with distinct temporal profiles, suggesting differential roles of these MKPs in the regulation of MAPK activation. Elevated activity of MKP-2 in $\alpha$ T3-1 cells, through either overexpression or activation of the endogenous MKP-2 gene, was correlated with inhibition of $\mathrm{GnRH}$-induced activation of ERK and JNK, as well as the expression of ERK- and JNK-dependent proto-oncogenes. These data supported the conclusion that GnRH-induced MKPs likely serve as negative feedback regulators that modulate MAPK activity and function in the GnRH signaling pathway.
\end{abstract}

Journal of Molecular Endocrinology (2005) 36, 41-50

\section{Introduction}

Gonadotropin-releasing hormone $(\mathrm{GnRH})$ activates the synthesis and release of the pituitary gonadotropins luteinizing hormone ( $\mathrm{LH}$ ) and follicle-stimulating hormone (FSH) (Gharib et al. 1990). LH and FSH play critical roles in the control of testicular and ovarian gametogenesis and steroidogenesis. GnRH is released from the hypothalamus in a pulsatile manner to regulate pituitary gonadotrope function (Clarke 1987, Clarke \& Cummins 1987). The intracellular effects of GnRH are mediated by a serpentine receptor coupled to a heterotrimeric $G$ protein in the $\mathrm{G}_{\mathrm{q} / 11}$ family (Hsieh \& Martin 1992, Stanislaus et al. 1998). Activated $G_{\alpha q}$ stimulates phospholipase $\mathrm{C}_{\beta}$, which leads to the generation of inositol 1,4,5-triphosphate $\left(\mathrm{IP}_{3}\right)$ and diacylglycerol (DAG). $\mathrm{IP}_{3}$ induces release of $\mathrm{Ca}^{2+}$ from intracellular stores, resulting in cytosolic $\mathrm{Ca}^{2+}$ oscillations. $\mathrm{Ca}^{2+}$ mobilization in gonadotropes plays a role in the secretion of gonadotropic hormones and transcriptional regulation of glycoprotein hormone subunit genes. DAG activates protein kinase $\mathrm{C}(\mathrm{PKC})$ isozymes, which are linked to transcriptional activation of the $\alpha$ subunit gene and proto-oncogenes regulated primarily by members of the MAP kinase (MAPK) family (Cesnjaj et al. 1993, Mitchell et al. 1994, Roberson et al. 1995, Sundaresan et al. 1996, Reiss et al. 1997) (for reviews see Stojilkovic et al. 1994, Hille et al. 1995, Naor et al. 1998).

Three major classes of MAPKs, extracellular signalregulated kinase (ERK), c-Jun N-terminal kinase (JNK) and p38, are activated following GnRH receptor occupancy in pituitary gonadotropes (Roberson et al. 1995, Sundaresan et al. 1996, Reiss et al. 1997). Activation of MAPK requires dual phosphorylation of threonine and tyrosine residues in the conserved TXY motif by MAPK kinase (Cobb \& Goldsmith 1995). A family of dual specificity protein phosphatases (MAPK phosphatases or MKPs) selectively downregulate MAPK activity both in vitro and in vivo by dephosphorylation of both tyrosine and threonine residues (hence the designation of dual specificity; Farooq \& Zhou 2004). MKPs have overlapping yet unique patterns of tissue distribution, subcellular localization (nuclear versus cytosolic), substrate specificity and response to mitogenic stimuli, suggesting that they may have distinct physiological functions (Lewis et al. 1998). The founding member of the family, MKP-1, is widely expressed in many proliferating and terminally differentiated cell types (Janknecht \& Nordheim 1992, Janknecht et al. 1992, 1994). In most cell lines studied to date, MKP-1 is activated as an immediate early gene in response to various stimuli, such as growth factors (Lau \& Nathans 1985), insulin (Kusari et al. 1997) and u.v. light (Liu et al. 1995, Bokemeyer et al. 1996). Several studies suggest that MKP-1 induction is ERK- or JNK-dependent and functions as a negative feedback mechanism to inactivate MAPKs (Bokemeyer et al. 1996, Brondello et al. 1997). A closely related MKP family member, MKP-2, is also widely expressed in a variety of cell lines and tissues. In pituitary 
gonadotropes, GnRH up-regulates the expression of MKP-2 through activation of the immediate early gene early growth response factor 1 (Egr-1) (Roberson et al. 1995, Zhang et al. 2001b). Induction of MKP-2 expression by $\mathrm{GnRH}$ is dependent on MAPK activation (Zhang et al. 2001a), suggesting potential feedback regulation within the GnRH signaling pathway by MKP-2. In the present study, we examined the role of MKP-1 and MKP-2 in the regulation of MAPK activity by GnRH. Using both an in vivo mouse model and the aT3-1 cell line, we observed distinct temporal profiles for the induction of MKP-1 and MKP-2 following GnRH treatment. Expression of MKP-1 and MKP-2 correlated with the activation and decline of MAPK activity, suggesting a role for these MKPs in the regulation of magnitude as well as the duration of MAPK activation. Through manipulation of MKP expression levels in $\alpha \mathrm{T} 3-1$ cells, we have shown that elevated MKP-2 was highly correlated with downregulation of ERK and JNK activity as well as ERKand JNK-dependent gene expression following GnRH stimulation. Overall, these studies support a role for MKPs as negative feedback regulators in the GnRH signaling pathway in the pituitary gonadotrope.

\section{Materials and methods}

\section{Materials}

The c-Fos, c-Jun, ERK2, JNK1, MKP-1 and MKP-2 antibodies, horseradish peroxidase (HRP)-conjugated secondary antibody and protein A/G-agarose were purchased from Santa Cruz Biotechnology (Santa Cruz, CA, USA). Phospho-specific (dual phosphorylated) ERK antibody was purchased from Promega (Madison, WI, USA). Phospho-specific JNK and MEK1/2 antibodies were purchased from Cell Signaling (Beverly, MA, USA). The MEK1 antibody was from Transduction Laboratories (Lexington, KY, USA). Phorbol 12myristate 13-acetate (PMA) and the GnRH agonist (GnRHa) buserelin were purchased from Sigma. Bacterial expression vector for Glutathione S-transferase-activating transcription factor 2 (GSTATF2) was from Dr Michael Green (University of Massachusetts, Worcester, MA, USA).

\section{Cell culture}

aT3-1 cells were a generous gift from Pamela Mellon (UC San Diego, CA, USA) and were grown to approximately 50\% confluence in Dulbecco's modified Eagle's medium (DMEM; Sigma) supplemented with $10 \%$ fetal bovine serum (Invitrogen, Carlsbad, CA, USA). The cells were then serum starved for $2 \mathrm{~h}$ in DMEM prior to administration of hormones and various agents.

\section{In vivo mouse model for GnRH action and transcript profiling of MKPs}

All experimental protocols used in these studies were approved by the Cornell University Institutional Animal Care and Use Committee. Female CF-1 mice (Charles River, Wilmington, MA, USA) were ovariectomized at 30 days of age and allowed 7-10 days recovery time. All animals were passively immunized against endogenous GnRH as has been described previously (Duval et al. 2000). Seventy-two hours later, mice were administered saline as control or $100 \mathrm{ng} \mathrm{dAla}{ }^{6}-\mathrm{GnRH}$ (Sigma), an agonist of $\mathrm{GnRH}$ not recognized by the immunoneutralizing antibody. All mice were killed by $\mathrm{CO}_{2}$ asphyxiation. Control animals $(n=6)$ were killed $120 \mathrm{~min}$ after saline injection. Mice receiving the $\mathrm{dAla}^{6}-\mathrm{GnRH}$ agonist were killed 20,40,60 and $120 \mathrm{~min}$ following injection ( $n=6 /$ time-point). Levels of LH in trunk blood were measured by specific RIA (Duval et al. 2000). Individual time-points were compared with the zero time-point by paired $t$-test and Bonferroni's procedure to determine statistical difference in serum concentrations of LH. Total cellular RNA was isolated from whole pituitaries using the Absolutely RNA isolation kit (Stratagene, La Jolla, CA, USA) as described by the manufacturer including treatment with DNase. DNAfree RNA samples isolated from individual animals were used in subsequent gene profiling studies described below.

SYBR green-based real-time PCR (qPGR) was performed as previously reported (Wurmbach et al. 2001). In brief, total RNA was converted into cDNA and $\sim 250 \mathrm{pg}$ was used for 40-cycle three-step PCR in an ABI Prism 7900HT (PE Applied Biosystems, Foster City, CA, USA) in $20 \mathrm{mM}$ Tris, $\mathrm{pH} 8 \cdot 4,50 \mathrm{mM} \mathrm{KCl}$, $3 \mathrm{mM} \mathrm{MgCl}_{2}, 200 \mu \mathrm{M}$ deoxynucleoside triphosphates, 0.5 SYBR Green I (Molecular Probes, Inc., Eugene, OR, USA), $200 \mathrm{nM}$ of each primer and $0.5 \mathrm{U}$ Platinum Taq (Invitrogen). Amplicon size and reaction specificity were confirmed by agarose gel electrophoresis. The relative levels of expression were interpolated from detection threshold (CT) values normalized relative to the CT of ribosomal protein S11 (RPS11), an unregulated housekeeping gene. Egr-1 and MKP transcripts in each sample were assayed twice, and the average CT values were used to calculate the fold change ratios between experimental and control samples for each gene used in the analysis. For statistical analysis, fold change values were log transformed and subjected to a paired $t$-test (comparing each time-point to time zero) followed by Bonferroni's procedure.

\section{Western blot analysis}

aT3-1 cells were cultured in $60 \mathrm{~mm}$ plates and treated as described. At the end of each experiment, cells were 
washed once with cold HEPES-buffered saline (20 mM HEPES, pH 7.5, $137 \mathrm{mM} \mathrm{NaCl}, 5 \mathrm{mM} \mathrm{KCl}, 1 \mathrm{mM}$ $\mathrm{Na}_{2} \mathrm{HPO}_{4}$ and $0 \cdot 1 \%$ dextrose) and lysed in RIPA buffer $(20 \mathrm{mM}$ Tris-HCl, pH $8 \cdot 0,137 \mathrm{mM}$ NaCl, $10 \%$ glycerol, $1 \%$ NP-40, $0 \cdot 1 \%$ SDS, $0.5 \%$ deoxycholate, $2 \mathrm{mM}$ EDTA, $5 \mathrm{mM}$ sodium vanadate, $0.2 \mathrm{mM}$ phenylmethylsulfonyl fluoride and $5 \mathrm{mM}$ benzamidine). Following centrifugation to remove cell debris, the whole cell lysates were resolved by 10\% SDS-PAGE and transferred to polyvinylidene difluoride membrane. The blots were blocked with 5\% non-fat dry milk (NFDM) in TBST $(10 \mathrm{mM}$ Tris-HCl, $\mathrm{pH} 7 \cdot 6,150 \mathrm{mM} \mathrm{NaCl}$ and $0.05 \%$ Tween-20) and then probed with primary antibody. MKP-1 and MKP-2 antibodies were diluted $1: 100$ in 5\% NFDM/TBST, c-Fos antibody was diluted 1:500 in 5\% NFDM/TBST, c-Jun, MEK1 and ERK2 antibodies were diluted $1: 1000$ in 5\% NFDM/TBST, phospho-specific ERK and JNK antibodies were diluted $1: 20000$ and $1: 1000$ (respectively) in $0 \cdot 1 \%$ bovine serum albumin (BSA)/TBST, and phospho-MEK 1/2 antibody was diluted 1:1000 in 5\% BSA/TBST. The above antibodies were incubated with the blots for either $2 \mathrm{~h}$ at room temperature or overnight at $4^{\circ} \mathrm{C}$. At the end of the incubation, the blots were washed in TBST, and then incubated with HRP-conjugated secondary antibody (1:5000 dilution in 5\% NFDM/TBST) for 30-60 min. After four washes in TBST, signals were detected using enhanced chemiluminescence (Perkin Elmer Life Sciences, Boston, MA, USA).

\section{JNK kinase assay}

JNK kinase assay was performed as previously described (Mulvaney et al. 1999, Mulvaney \& Roberson 2000). Briefly, whole cell lysates were prepared in the same way as described for western blot analysis. JNK activity was immunoprecipitated with JNK1 antibody and protein $\mathrm{A} / \mathrm{G}$-agarose. The kinase reaction was carried out at $30{ }^{\circ} \mathrm{C}$ for $30 \mathrm{~min}$ using GST-ATF2 as substrate. After resolving by $10 \%$ SDS-PAGE, the phosphorylated GST-ATF2 was visualized by autoradiography. In some experiments, phospho-specific JNK antibody and Western analysis was substituted for the in vitro kinase assay for ease of experimentation. Results from the JNK catalytic assay and the phospho-specific antibody were similar. In some cases for both the ERK and JNK data, individual bands at time zero and $30 \mathrm{~min}$ following GnRH administration were quantitated using densiotometry and data were compared by analysis of variance and Tukey's Studentized range test.

\section{Transient transfection}

$\alpha$ T3-1 cells were cultured in $60 \mathrm{~mm}$ plates to $20-50 \%$ confluence before transfection. The expression vector for MKP-2 was co-transfected into $\alpha$ T3-1 cells with the

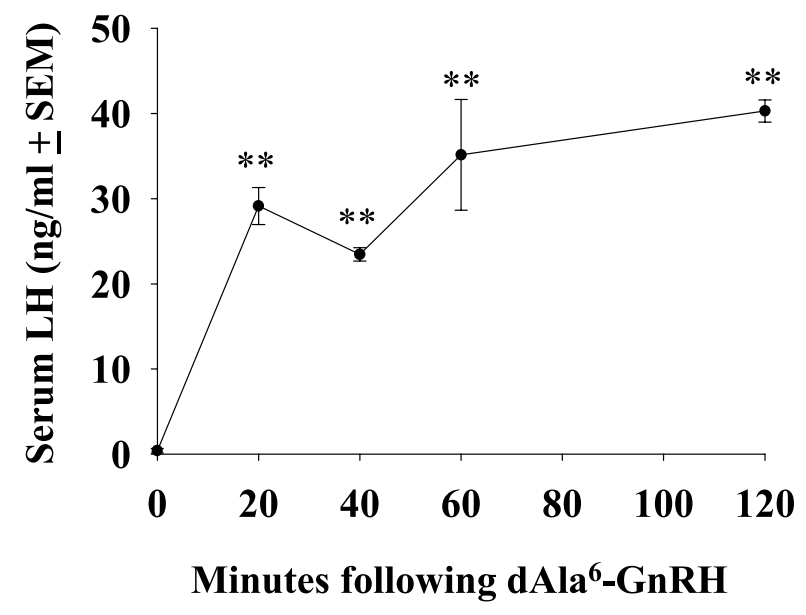

Figure $1 \mathrm{LH}$ secretion following $\mathrm{dAla}^{6}-\mathrm{GnRH}$ agonist treatment in mice. Ovariectomized female CF-1 mice were passively immunized against endogenous $\mathrm{GnRH}$. Seventy-two hours later, the mice were administered $100 \mathrm{ng}$ dAla6-GnRH. Trunk blood samples were collected at the indicated time-points and levels of LH were measured by RIA. Data are presented as means \pm S.E.M. ( $n=6 /$ time-point). ${ }^{* \star} P<0.05$ compared with time zero.

expression vectors for ERK and JNK using SuperFect transfection reagent (Qiagen, Valencia, CA, USA) according to the manufacturer's protocol. The total amount of DNA was kept constant by adding appropriate amounts of pcDNA3 vector. Total DNA $(12 \mu \mathrm{g})$ and SuperFect reagent $(50 \mu \mathrm{l})$ (Qiagen) were used in each transfection. Whole cell lysates were collected $36 \mathrm{~h}$ after the transfection and western blot analysis was performed as described above.

\section{Results}

\section{Temporal correlation between the induction of MKP-1, MKP-2 and activation of MAPKs}

Induction of MKPs by GnRH suggests a negative feedback mechanism that controls MAPK activity in pituitary gonadotropes. To investigate this possibility, we examined the activation profile of these signaling components following GnRH treatment. First, we studied MKP-1, MKP-2 and Egr-1 mRNA expression using an in vivo mouse model for GnRH pulse stimulation. Passive immuno-neutralization of endogenous GnRH in ovariectomized mice was a useful paradigm to deliver a timed administration of $\mathrm{dAla}^{6}-$ $\mathrm{GnRH}$ agonist and collect tissues to determine the expression profile of GnRH-responsive genes. Following GnRH immunoneutralization, serum LH dropped to very low levels $(0 \cdot 41 \pm 0.27 \mathrm{ng} / \mathrm{ml}$, time 0 in Fig. 1), demonstrating the efficacy of the GnRH antisera (Duval et al. 2000). Within $20 \mathrm{~min}$ of $\mathrm{dAla}^{6}-\mathrm{GnRH}$ 
administration, LH secretion increased markedly and remained elevated for the duration of the study (Fig. 1). Correlated with the LH secretory response, mRNA levels for Egr-1, MKP-1 and MKP-2 were increased albeit with differing kinetics (Fig. 2). MKPs and Egr-1 mRNA have been shown to be up-regulated by GnRH using the L $\beta$ T2 cell model and array/qPCR approaches (Wurmbach et al. 2001). Egr-1 was shown to be necessary for the expression of the LH $\beta$ subunit promoter and Egr-1 null mice are infertile due to lack of LH (Lee et al. 1996, Topilko et al. 1998). Our laboratory has shown previously that Egr-1 is also involved in the regulation of the MKP-2 gene promoter in $\alpha \mathrm{T} 3-1$ cells; (Zhang et al. 2001b). In vivo, Egr-1 mRNA levels increased $11 \cdot 7 \pm 1 \cdot 5$-fold (means \pm S.E.M.; $P<0 \cdot 05$ ) by 20 min following the $\mathrm{dAla}^{6}-\mathrm{GnRH}$ pulse, and declined to baseline by $120 \mathrm{~min}$. The kinetics of MKP-1 mRNA expression was similar to Egr-1 with a rapid induction $(5 \cdot 8 \pm 0 \cdot 5$-fold; $P<0 \cdot 05)$ followed by a return to baseline by $40 \mathrm{~min}$ after the $\mathrm{dAla}^{6}-\mathrm{GnRH}$ pulse. In contrast, MKP-2 mRNA was elevated $1.98 \pm 0 \cdot 53$-fold $(P<0 \cdot 07)$ at $60 \mathrm{~min}$ following the $\mathrm{dAla}^{6}-\mathrm{GnRH}$ pulse. Thus, two overlapping mRNA profiles exist for MKP expression induced by GnRH in vivo, a rapid rise in MKP-1 expression followed by a later increase in the expression of MKP-2 mRNA. Importantly, these mRNA induction profiles were consistent with the protein expression profiles observed in $\alpha \mathrm{T} 3-1$ cells previously (Zhang et al. 2001a).

Next, we examined the time-course of MKP-1 and MKP-2 protein expression and ERK and JNK phosphorylation/activation in $\alpha \mathrm{T} 3-1$ cells following treatment with the GnRHa buserelin (Fig. 3). Consistent with the in vivo mRNA data, the expression of MKP-1 and MKP-2 proteins temporally overlapped with each other, but each followed a distinct time-course. After GnRHa treatment, MKP-1 protein amounts increased to high levels within $30 \mathrm{~min}$, peaked at $1 \mathrm{~h}$, and had declined to near baseline within $4 \mathrm{~h}$. MKP-2 protein amounts increased gradually and reached the peak level $2 \mathrm{~h}$ after GnRHa treatment. MKP-2 protein declined gradually thereafter, but remained at measurable levels $8 \mathrm{~h}$ following hormone treatment (data not shown). Comparing in vivo mRNA data (Fig. 2) with protein data (Fig. 3) reveals that much greater differences exist when examining expression of MKPs at the protein levels. This may reflect differences comparing in vivo conditions with clonal $\alpha \mathrm{T} 3-1$ cells. We also cannot rule out the possibility that there may be differential regulation of MKPs at the transcriptional and translational levels. When the activation time-course of the MKPs was compared with that of ERK and JNK following GnRHa administration, the maximal level of MKP-2 appears to be temporally associated with the apparent dephosphorylation/inactivation of ERK and JNK (Fig. 3). The phospho-specific ERK antibody requires

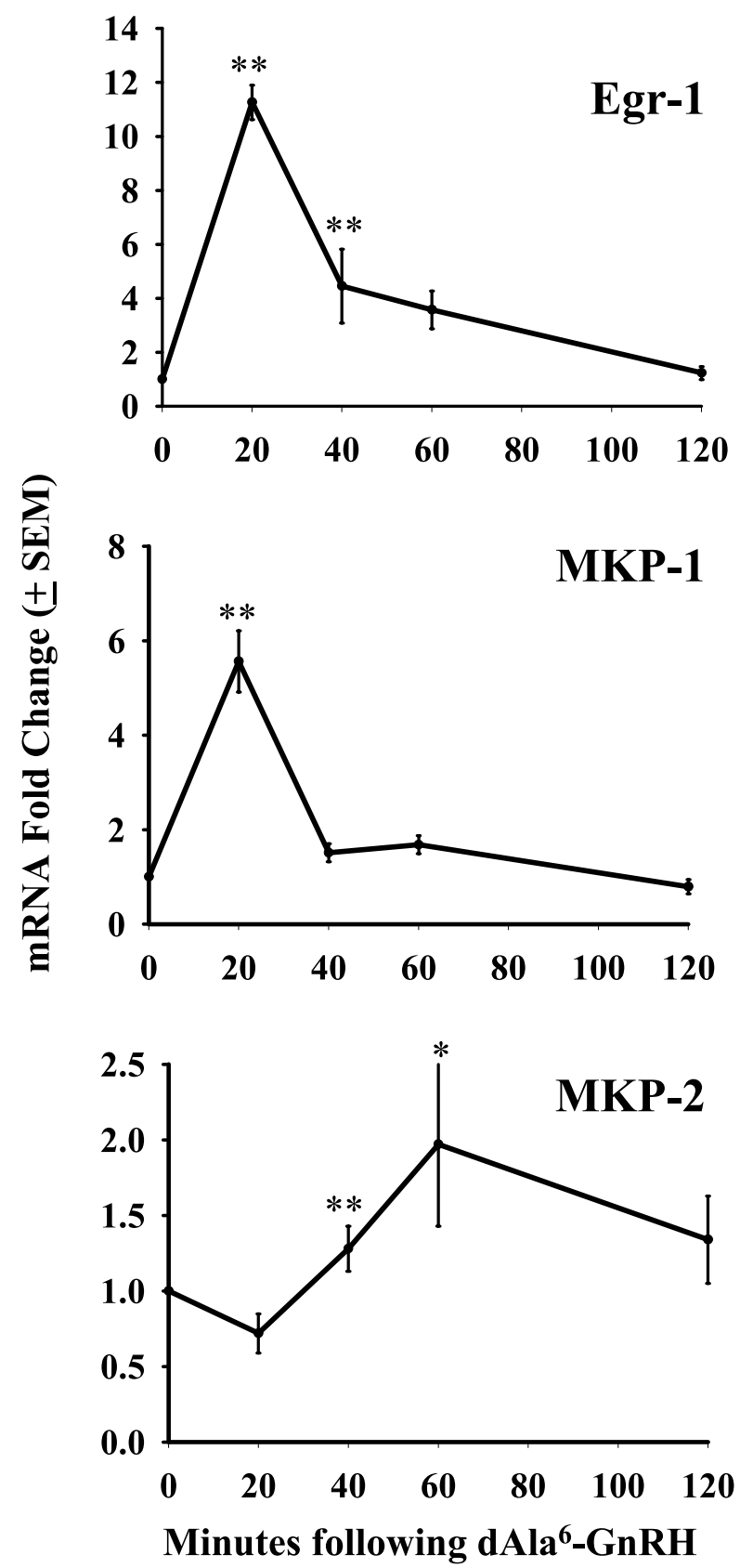

Figure 2 Time-course of Egr-1, MKP-1 and MKP-2 mRNA induction following $\mathrm{dAla}^{6}-\mathrm{GnRH}$ agonist treatment in mice. Ovariectomized female CF-1 mice were passively immunized against endogenous $\mathrm{GnRH}$. Seventy-two hours later, the mice were administered saline as control or $100 \mathrm{ng} \mathrm{dAla}^{6}-\mathrm{GnRH}$.

Total cellular RNA was isolated from whole pituitaries at indicated time-points (control samples were collected at 120 min after saline injection). Relative mRNA levels were determined by real-time PCR, and normalized to the housekeeping gene RPS11. Fold change of each gene product following dAla ${ }^{6}-\mathrm{GnRH}$ administration was determined by transcript ratios between experimental and control samples. Data are presented as means \pm S.E.M. ( $n=6 /$ time-point). ${ }^{*} P<0.07,{ }^{*} P<0.05$ compared with time zero. 


\section{GnRHa (h)}

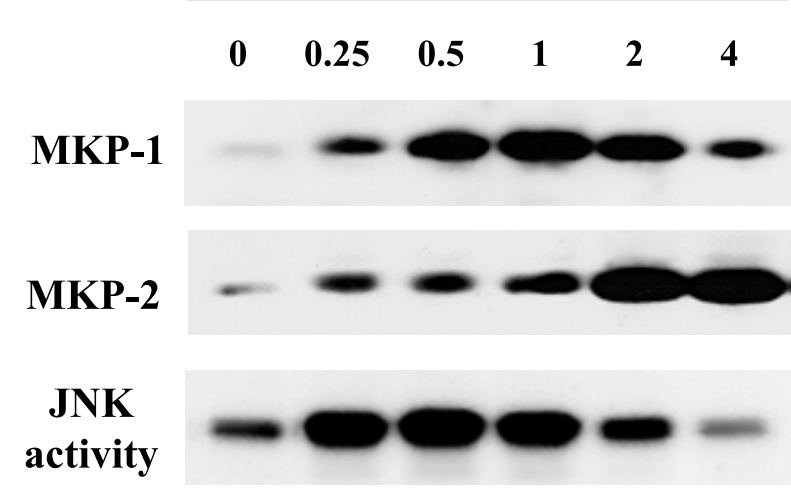

phospho
ERK

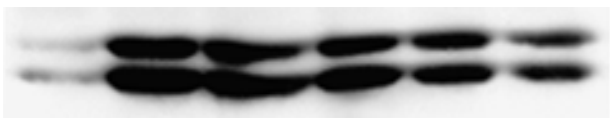

ERK

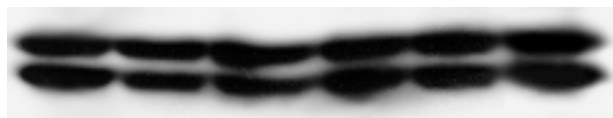

Figure 3 Temporal correlation between MKP induction and MAPK activation following GnRH stimulation. $\alpha$ T3-1 cells were serum starved for $2 \mathrm{~h}$ and then treated with the $\mathrm{GnRHa}$ buserelin $(10 \mathrm{nM})$ for the times indicated. Active ERK amounts were detected by western blot analysis using phospho-specific ERK antibody (phospho ERK). Total ERK amounts were also examined on the same blot to verify equivalent protein loading. JNK activity was measured by kinase assay using JNK1 antibody for immuno-precipitation and GST-ATF2 as substrate for kinase reaction. The products of the JNK kinase reaction were resolved by SDS-PAGE and visualized by autoradiography. MKP-1 and MKP-2 protein amounts were analyzed by western blotting. These studies were completed at least three times on separate occasions.

dual phosphorylation of ERK for immunoreactivity, thus reflecting the activation state of the ERK enzymes. These correlative data were consistent with a role of MKP-2 in controlling the duration of GnRH-induced MAPK activation. MKP-1 expression overlapped with the peak activity of both ERK and JNK, suggesting that MKP-1 may regulate the magnitude as well as the duration of MAPK activation upon GnRH stimulation.

\section{Effects of MKP-2 overexpression on the activation of ERK and JNK in aT3-1 cells}

Our results in Fig. 3 demonstrate a strong temporal correlation between the induction of MKP-2 and the inactivation of ERK and JNK. Based on this observation, we further tested the function of MKP-2 in GnRH signaling pathways using overexpression studies in $\alpha \mathrm{T} 3-1$ cells. Exogenous overexpression of MKP-2

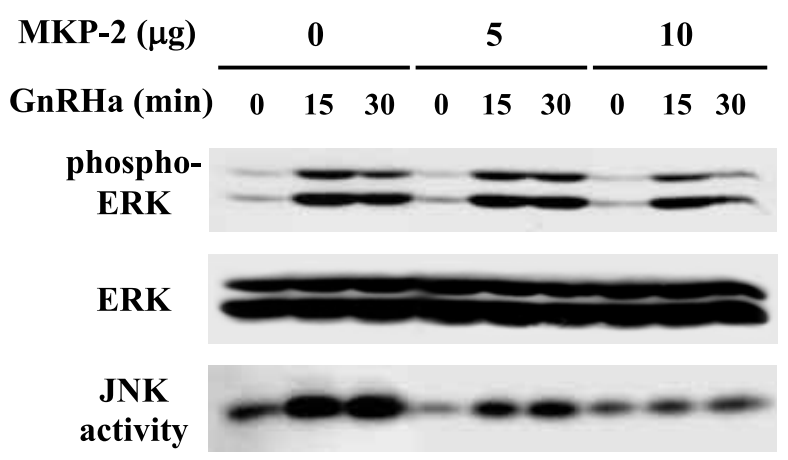

Figure 4 Overexpression of MKP-2 inhibited GnRH-induced JNK activation. $\alpha$ T3-1 cells were transfected with increasing amounts of full-length MKP-2 expression vector. The total amount of DNA was kept constant by adding appropriate amounts of pcDNA3 vector. Thirty-four hours after the transfection, the cells were serum starved for $2 \mathrm{~h}$, followed by $\mathrm{GnRHa}$ administration for the times indicated. Whole cell lysate was collected and phospho-ERK and total ERK amounts were analyzed by western blotting. JNK kinase activity of the same samples was detected by immuno-precipitation followed by kinase assay.

primarily inhibited GnRH-induced phosphorylation/ activation of JNK and to a lesser extent ERKs (Fig. 4). At a higher dose of MKP-2 expression vector, induction of JNK catalytic activity was reduced (control 2.58 \pm $0 \cdot 3$-fold versus MKP-2 overexpression $1 \cdot 34 \pm 0 \cdot 1$-fold at the 30-min time-point; $P<0 \cdot 05)$, while ERK dephosphorylation was numerically reduced (control $5 \cdot 11 \pm 0 \cdot 4$ fold versus MKP-2 overexpression 2.96 $\pm 0 \cdot 6$-fold); however, this difference did not reach statistical significance. These results provide direct evidence that elevated expression of MKP-2 inhibits GnRH signaling through JNK in $\alpha \mathrm{T} 3-1$ cells. Together with the MKP-2 expression profile following GnRH treatment (Figs 2 and 3 , these data are consistent with a role of MKP-2 as a negative feedback regulator of JNK-dependent GnRH signaling.

\section{Down-regulation of MAPK activity by GnRH-induced MKP-2 in $\alpha$ T3-1 cells}

GnRHa pulse pretreatment elevates endogenous MKP-2 levels

To further investigate the function of $\mathrm{GnRH}$-induced MKP-2, we sought to examine GnRH-dependent MAPK activation in the presence of elevated endogenous MKP-2 levels. As shown in Fig. 3, $4 \mathrm{~h}$ after GnRHa stimulation MKP-2 protein remained at maximal levels while ERK and JNK activity declined to near basal levels. This allowed us to compare ERK and JNK activation by GnRHa during times when cells have low amounts of MKP-2 (time 0) and times when MKP-2 amounts were markedly elevated $(4 \mathrm{~h})$. Initially, we 
A

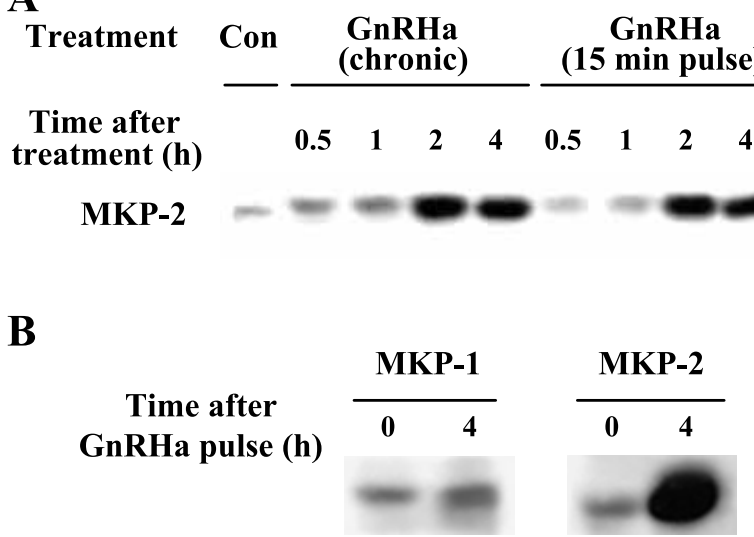

Figure 5 Chronic and 15-min pulse treatment of GnRHa had similar effects on MKP induction. (A) MKP-2 induction was examined following chronic or pulsatile GnRHa treatment. In parallel studies, groups of $\alpha \mathrm{T} 3-1$ cells were treated with $\mathrm{GnRHa}(10 \mathrm{nM})$ either chronically or as a 15-min pulse (beginning at time 0 ) followed by washing and maintenance in hormone-free medium. Cells were collected at the time-points indicated. MKP-2 protein amounts were examined by western blot analysis. (B) $\alpha \mathrm{T} 3-1$ cells were treated with a 15-min $\mathrm{GnRHa}$ pulse as described in (A). Whole cell lysate was collected at 0 and $4 \mathrm{~h}$ after the treatment, and MKP-1 and MKP-2 protein amounts were analyzed by Western blotting. These studies were completed at least three times on separate occasions.

examined whether a single 15-min pulse of GnRHa was sufficient to activate MKP-2 expression similar to the effect of chronic GnRHa treatment. The GnRHa pulse treatment had the same effects on the activation of MKP-2 (Fig. 5A), ERK and JNK (data not shown) as the chronic hormone treatment. The 15-min GnRHa pulse provided an experimental paradigm that resulted in minimal hormone-induced down-regulation of $\mathrm{GnRH}$ receptors (Hawes \& Conn 1992) which was an important consideration for subsequent studies.

We then compared the expression of MKP-1 and MKP-2 following the GnRHa pulse treatment. Consistent with the data shown in Fig. 3, $4 \mathrm{~h}$ after the GnRHa pulse MKP-1 levels were basal while MKP-2 levels were near maximum (Fig. 5B). These control studies support the notion that MKP-1 would have minimal contribution to MAPK inactivation within this time-frame. Conversely, MKP-2 induced by GnRH would likely play a prominent role in MAPK inactivation $4 \mathrm{~h}$ following a GnRHa pulse pretreatment.

GnRHa pulse pretreatment inhibits ERK and JNK activation as well as ERK- and JNK-regulated gene expression

To examine the effect of the GnRHa pulse pretreatment on MAPK activation, $\alpha \mathrm{T} 3-1$ cells were treated with or
GnRHa (h)

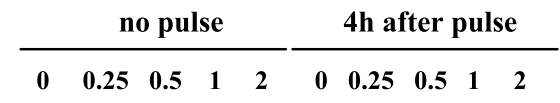

Phospho-JNK

Phospho-ERK

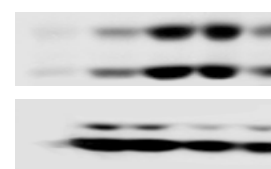

ERK

MKP-2
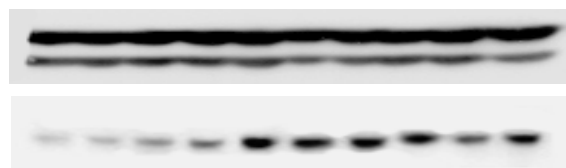

Figure 6 Elevated expression of endogenous MKP-2 was correlated with reduced MAPK activation by GnRHa. $\alpha \mathrm{T} 3-1$ cells were treated with or without a 15-min pulse of $\mathrm{GnRHa}$ $(10 \mathrm{nM})$ as described in Fig. 5. Four hours following the $\mathrm{GnRHa}$ pulse, the cells were stimulated again with $\mathrm{GnRHa}$ $(10 \mathrm{nM})$ for the times indicated. Phospho-ERK and total ERK amounts were determined by western blotting. JNK activity was measured by immuno-precipitation followed by kinase assay. These studies were completed at least three times on separate occasions.

without a single 15-min pulse of $\mathrm{GnRHa}$, followed by wash out of the hormone. Four hours later, the cells were stimulated again with GnRHa and the activation of ERK and JNK was examined. In pre-pulsed cells, GnRHa-induced ERK and JNK phosphorylation/ activation was reduced in magnitude, and JNK activity was shortened in duration by $\sim 1 \mathrm{~h}$ (Fig. 6). These studies were consistent with overexpression of MKP-2 relative to JNK activity (Fig. 4). Interestingly, inhibition of ERK phosphorylation was more evident in these studies using the GnRHa pulse paradigm. The possibility exists that endogenous MKP-2 expression levels were greater relative to levels achieved using overexpression of the MKP-2 expression vector in earlier studies. Thus, within the context of elevated levels of endogenous MKP-2 and basal levels of MKP-1, GnRHa-induced activation of ERK and JNK was attenuated.

Next, we examined the effect of the GnRHa pulse pretreatment on the activation of ERK- and JNKregulated immediate early genes, c-Fos and c-Jun. When the same pulse paradigm as in Fig. 6 was used, GnRHa induction of c-Fos expression $4 \mathrm{~h}$ following the initial GnRHa pulse treatment was profoundly reduced in $\alpha \mathrm{T} 3-1$ cells (Fig. 7). c-Jun is a specific substrate for the JNK pathway. The phosphorylation state of c-Jun was examined by western blot analysis where phosphorylated c-Jun migrates more slowly on SDS-PAGE. Consistent with the reduction in JNK activation, phosphorylation of c-Jun and up-regulation of c-Jun protein amounts were greatly reduced by the GnRHa pulse pretreatment (Fig. 7). Overall, these studies provided correlative data to support the notion that 


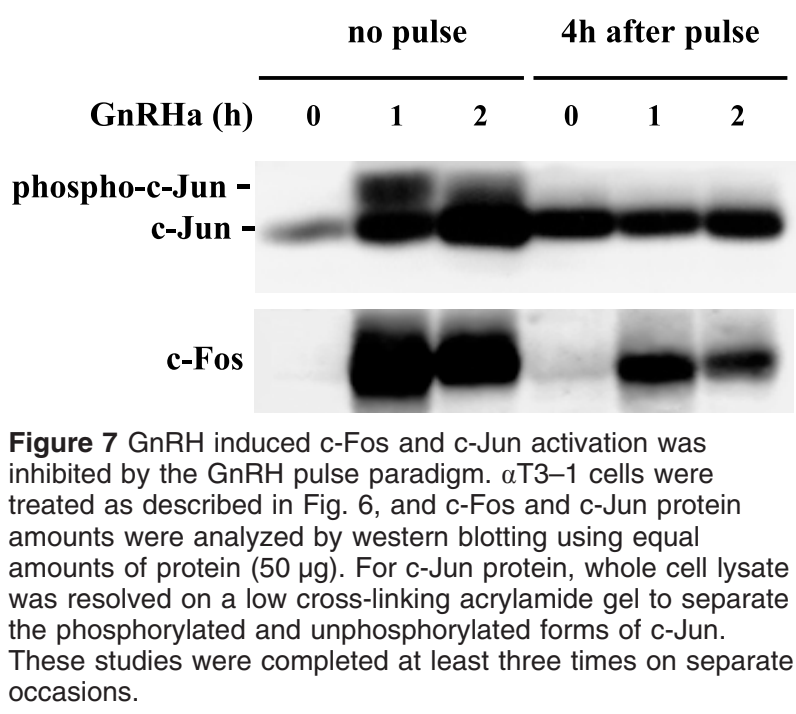

endogenous phosphatase activity including MKP-2 may serve as a negative feedback regulator of ERK and JNK functions in the GnRH signaling pathway.

The reduced activation of ERK in the pre-pulsed cells is not due to upstream desensitization events

To verify that the reduced effect of the second GnRHa treatment on ERK activation was not caused by possible desensitization of upstream signaling events, we conducted two control studies. In one study, GnRHa was used for the first pulse treatment to elevate MKP-2 protein amounts; however, phorbol ester was used for the second stimulation effectively bypassing the $\mathrm{GnRH}$ receptor and signaling components upstream of PKC. The GnRHa pulse pretreatment had a similar inhibitory effect on PMA-induced ERK activation (Fig. 8A). This result indicated that signaling events downstream of PKC activation were attenuated by the pulse pretreatment. In the second study, we examined the activation of MEK1/2, the immediate upstream activators of ERK1 and ERK2, in the same pulse paradigm as used in Fig. 6. The pulse pretreatment did not alter the activation pattern of MEK $1 / 2$ up to $2 \mathrm{~h}$ following the second GnRHa treatment (Fig. 8B). These data strongly argue that the reduced activation of ERKs in the pre-pulsed cells was not due to desensitization events that might occur upstream of ERK activation. Taken together, our data suggest that elevated endogenous dual specificity phosphatases (such as MKP-2) in the GnRHa-pretreated cells may play a role in inhibition of ERK activation by the second GnRHa stimulation.
$\mathbf{A}$

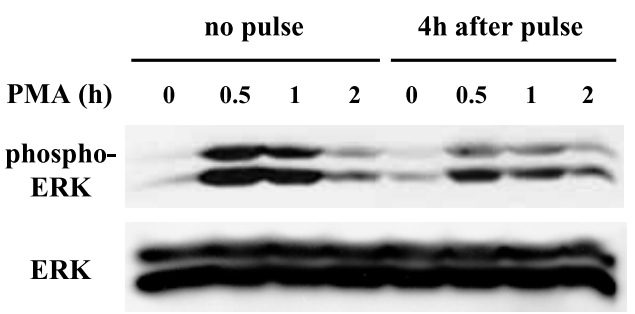

B

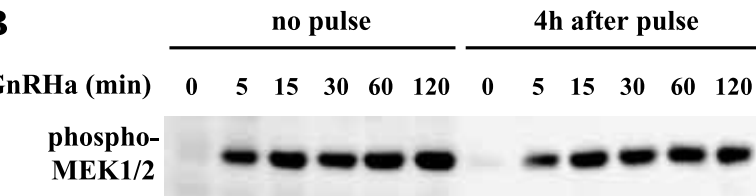

MEK1

Figure 8 The attenuated ERK activity in the pulse paradigm did not result from desensitization upstream of ERK activation. (A) $\alpha \mathrm{T} 3-1$ cells were treated with or without a 15-min pulse of $\mathrm{GnRHa}(10 \mathrm{nM})$ as described in Fig. 5. Four hours following the GnRHa pulse, the cells were stimulated again by PMA $(1 \mu \mathrm{M})$ for the times indicated. Phospho-ERK and total ERK amounts were determined by western blot analysis. (B) $\alpha \mathrm{T} 3-1$ cells were treated in the same way as described in Fig. 6. Phospho-MEK1/2 amount and total MEK1 amount were determined by western blot analysis. These studies were completed at least three times on separate occasions.

\section{Discussion}

MAPK cascades are key components of signaling pathways that integrate extracellular stimuli to nuclear events such as gene transcription (for reviews see Cobb \& Goldsmith 1995, Lewis et al. 1998). MAPK activity is determined by the balance between specific activating kinases and inactivating phosphatases. Dual-specificity MKPs have been shown to selectively inactivate MAPKs. MKP activities are controlled primarily at the level of gene expression (for review see Lewis et al. 1998). In vivo induction of MKP expression by $\mathrm{dAla}^{6}-\mathrm{GnRH}$ in the mouse model (Figs 1 and 2) confirms our previous report on the regulation of MKPs in both cultured primary gonadotropes and $\alpha \mathrm{T} 3-1$ cells. These in vivo results suggest that both MKP-1 and MKP-2 may be crucial effectors in the GnRH signaling pathway under physiological conditions.

To further investigate the function of MKPs in GnRH signaling, we used the $\alpha \mathrm{T} 3-1$ cell model. The close temporal correlation between GnRHa-induced MKP-1 and MKP-2 expression and inactivation of MAPKs was consistent with the notion that these MKPs regulate the magnitude and duration of MAPK activation. Further, MKP-2 overexpression provided clear evidence that MKP-2 is sufficient to dephosphorylate and thus inactivate the catalytic activity of JNK. Based upon these 
observations, we have used a model experimental paradigm in which a GnRHa pulse pretreatment was sufficient to elevate endogenous MKP-2 levels and to attenuate MAPK signaling and proto-oncogene expression following subsequent GnRHa stimulation. The expression profile of MKP-2 in this experimental paradigm suggests that it may be an important factor responsible for the reduced activation of MAPKs. These studies provide a novel view of $\mathrm{GnRH}$ action in which $\mathrm{GnRH}$ desensitizes gonadotrope cell function through activation of MKPs. The mechanisms of cellular desensitization by chronic or acute hormone exposure via serpentine receptors have not been fully described. Chronic exposure to GnRH agonists has been linked to desensitization of GnRH-induced hormone secretion (Chang et al. 1988, Gorospe \& Conn 1988, Hawes \& Conn 1992, Mason et al. 1994, McArdle et al. 1996) and losses in GnRH receptor mRNA in pituitary gonadotropes (Chang et al. 1988, Pinski et al. 1996). In contrast, secretory and signaling desensitization of gonadotropes has also been observed immediately following acute exposures to GnRH (Anderson et al. 1995, Weiss et al. 1995). Our studies differed from these reports in that a single GnRHa pulse was sufficient to modulate $\mathrm{GnRH}$ responsiveness $4 \mathrm{~h}$ later. This result suggests that GnRH inter-pulse interval may be an important determinant of MAPK functions in GnRH-responsive gonadotropes. Additional in vivo studies are required to test this hypothesis.

In conducting the GnRHa pulse studies, one major concern was that response to GnRHa stimulation $4 \mathrm{~h}$ following the initial 15-min pulse may be influenced by down-regulation of GnRH receptors after the initial pulse. While we cannot completely discount this possibility, our two control studies support the notion that attenuation of ERK activities following the second agonist stimulation was likely associated with increased cellular amounts of MKP-2 and related dual-specificity phosphatases. When PMA was used as the second agonist in the GnRH pulse paradigm, it functionally bypassed potential desensitization events upstream of the PKC isozymes, including loss of GnRH receptors. In addition, it is unlikely that the GnRHa pulse treatment can cause PKC depletion over the 4-h experimental period since chronic GnRH treatment did not result in significant loss of PKG in $\alpha \mathrm{T} 3-1$ cells (McArdle et al. 1987, Kratzmeier et al. 1996). Therefore, the result from the PMA study (Fig. 8A) indicated that signaling components downstream of PKG contribute to the desensitization of ERK activation in response to the initial GnRHa pulse. Consistent with this, our study on MEK1/2 activation (Fig. 8B) also indicated that this desensitization occurs downstream of MEK1/2. Thus, we were able to discount other potential effectors of cellular desensitization by GnRH action, lending support to the hypothesis that accumulation of MKP-2 (or related phosphatases) may play a functional role in determining cellular sensitivity to GnRH action on MAPK-dependent processes.

Our studies with the GnRH pulse paradigm were consistent with the studies of others in examining the role of MKPs in the down-regulation of MAPK signals. In PG12 cells, induction of MKP-1 and MKP-2 by nerve growth factor blocked u.v. light-induced JNK activation 2 h later (Hirsch \& Stork 1997). In a separate study, basic fibroblast growth factor (bFGF) caused prolonged expression of MKP-3, which inhibited ERK activation up to 2 days after the bFGF treatment (Camps et al. 1998). On the other hand, inhibition of MKP-1 expression in rat mesangial cells has been shown to prolong JNK and c-Jun activation and potentiate JNK-mediated apoptosis (Guo et al. 1998). These data, together with our study in $\alpha \mathrm{T} 3-1$ cells, provide evidence that MKPs are physiological regulators of MAPK pathways and downstream effectors of these cascades. This idea may be of particular importance to the GnRH system since the inter-pulse interval leading to $\mathrm{LH}$ pulsatility can vary greatly depending upon the physiological state.

\section{Acknowledgements}

We are indebted to Drs P Mellon and M Green for generously providing critical reagents. A special thanks goes to Dr Stuart Sealfon and colleagues for help with qPCR for MKP-1, MKP-2 and Egr-1 and to Ms Li Han for aid with statistical analyses. The studies presented were supported by a grant from the National Institutes of Health (HD34772) to M S R. The authors declare that there is no conflict of interest that would prejudice the impartiality of this scientific work.

\section{References}

Anderson L, McGregor A, Cook JV, Chilvers E \& Eidne KA 1995 Rapid desensitization of GnRH-stimulated intracellular signalling events in alpha T3-1 and HEK-293 cells expressing the GnRH receptor. Endocrinology 136 5228-5231.

Bokemeyer D, Sorokin A, Yan M, Ahn NG, Templeton DJ \& Dunn MJ 1996 Induction of mitogen-activated protein kinase phosphatase 1 by the stress-activated protein kinase signaling pathway but not by extracellular signal-regulated kinase in fibroblasts. Fournal of Biological Chemistry 271 639-642.

Brondello JM, Brunet A, Pouyssegur J \& McKenzie FR 1997 The dual specificity mitogen-activated protein kinase phosphatase-1 and -2 are induced by the p $42 / \mathrm{p} 44$ MAPK cascade. Fournal of Biological Chemistry 272 1368-1376.

Camps M, Chabert C, Muda M, Boschert U, Gillieron C \& Arkinstall S 1998 Induction of the mitogen-activated protein kinase phosphatase MKP3 by nerve growth factor in differentiating PC12. FEBS Letters 425 271-276.

Cesnjaj M, Krsmanovic LZ, Catt KJ \& Stojilkovic SS 1993 Autocrine induction of c-fos expression in GT1 neuronal cells by gonadotropin-releasing hormone. Endocrinology 133 3042-3045. 
Chang JP, Graeter JS \& Catt KJ 1988 Desensitization of pituitary gonadotropes by mediators of LH release. Biochemical and Biophysical Research Communications 153 919-924.

Clarke IJ 1987 Control of GnRH secretion. Fournal of Reproduction and Fertility 34 (Suppl) 1-8.

Clarke IJ \& Cummins JT 1987 Pulsatility of reproductive hormones: physiological basis and clinical implications. Baillieres Clinical Endocrinology and Metabolism 1 1-21.

Cobb MH \& Goldsmith EJ 1995 How MAP kinases are regulated. Journal of Biological Chemistry 270 14843-14846.

Duval DL, Farris AR, Quirk CG, Nett TM, Hamernik DL \& Clay CM 2000 Responsiveness of the ovine gonadotropin-releasing hormone receptor gene to estradiol and gonadotropin-releasing hormone is not detectable in vitro but is revealed in transgenic mice. Endocrinology 141 1001-1010.

Faroog A \& Zhou MM 2004 Structure and regulation of MAPK phosphatases. Cellular Signaling 16 769-779.

Gharib SD, Wierman ME, Shupnik MA \& Chin WW 1990 Molecular biology of the pituitary gonadotropins. Endocrine Revierws 11 177-199.

Gorospe WC \& Conn PM 1988 Restoration of the LH secretory response in desensitized gonadotropes. Molecular and Cellular Endocrinology 59 101-110.

Guo YL, Kang B \& Williamson JR 1998 Inhibition of the expression of mitogen-activated protein phosphatase- 1 potentiates apoptosis induced by tumor necrosis factor-alpha in rat mesangial cells. fournal of Biological Chemistry 273 10362-10366.

Hawes BE \& Conn PM 1992 Development of gonadotrope desensitization to gonadotropin- releasing hormone $(\mathrm{GnRH})$ and recovery are not coupled to inositol phosphate production or GnRH receptor number. Endocrinology 131 2681-2689.

Hille B, Tse A, Tse FW \& Bosma MM 1995 Signaling mechanisms during the response of pituitary gonadotropes to GnRH. Recent Progress in Hormone Research 50 75-95.

Hirsch DD \& Stork PJ 1997 Mitogen-activated protein kinase phosphatases inactivate stress-activated protein kinase pathways in vivo. Fournal of Biological Chemistry 272 4568-4575.

Hsieh KP \& Martin TF 1992 Thyrotropin-releasing hormone and gonadotropin-releasing hormone receptors activate phospholipase $\mathrm{C}$ by coupling to the guanosine triphosphate-binding proteins $\mathrm{Gq}$ and G11. Molecular Endocrinology 6 1673-1681.

Janknecht R \& Nordheim A 1992 Elk-1 protein domains required for direct and SRF-assisted DNA- binding. Nucleic Acids Research 20 3317-3324.

Janknecht R, Hipskind RA, Houthaeve T, Nordheim A \& Stunnenberg HG 1992 Identification of multiple SRF N-terminal phosphorylation sites affecting DNA binding properties. EMBO Fournal 11 1045-1054.

Janknecht R, Zinck R, Ernst WH \& Nordheim A 1994 Functional dissection of the transcription factor Elk-1. Oncogene 9 1273-1278.

Kratzmeier M, Poch A, Mukhopadhyay AK \& McArdle CA 1996 Selective translocation of non-conventional protein kinase $\mathrm{C}$ isoenzymes by gonadotropin-releasing hormone $(\mathrm{GnRH})$ in the gonadotrope-derived $\alpha \mathrm{T} 3-1$ cell line. Molecular and Cellular Endocrinology 118 103-111.

Kusari AB, Byon J, Bandyopadhyay D, Kenner KA \& Kusari J 1997 Insulin-induced mitogen-activated protein (MAP) kinase phosphatase-1 (MKP-1) attenuates insulin-stimulated MAP kinase activity: a mechanism for the feedback inhibition of insulin signaling. Molecular Endocrinology 11 1532-1543.

Lau LF \& Nathans D 1985 Identification of a set of genes expressed during the G0/G1 transition of cultured mouse cells. EMBO fournal 4 3145-3151.

Lee SL, Sadovsky Y, Swirnoff AH, Polish JA, Goda P, Gavrilina G \& Milbrandt J 1996 Luteinizing hormone deficiency and female infertility in mice lacking the transcription factor NGFI-A (Egr-1). Science 273 1219-1221.
Lewis TS, Shapiro PS \& Ahn NG 1998 Signal transduction through MAP kinase cascades. Advances in Cancer Research 74 49-139.

Liu Y, Gorospe M, Yang C \& Holbrook NJ 1995 Role of mitogen-activated protein kinase phosphatase during the cellular response to genotoxic stress. Inhibition of c-Jun $\mathrm{N}$-terminal kinase activity and AP-1-dependent gene activation. Fournal of Biological Chemistry 270 8377-8380.

McArdle CA, Gorospe WC, Huckle WR \& Conn PM 1987 Homologous down-regulation of gonadotropin-releasing hormone receptors and desensitization of gonadotropes: lack of dependence on protein kinase C. Molecular Endocrinology 1 420-429.

McArdle CA, Willars GB, Fowkes RC, Nahorski SR, Davidson JS \& Forrest-Owen W 1996 Desensitization of gonadotropin-releasing hormone action in alphaT3-1 cells due to uncoupling of inositol 1,4,5-trisphosphate generation and Ca2+ mobilization. Fournal of Biological Chemistry $27123711-23717$.

Mason DR, Arora KK, Mertz LM \& Catt KJ 1994 Homologous down-regulation of gonadotropin-releasing hormone receptor sites and messenger ribonucleic acid transcripts in alpha T3-1 cells. Endocrinology 135 1165-1170.

Mitchell R, Sim PJ, Leslie T, Johnson MS \& Thomson FJ 1994 Activation of MAP kinase associated with the priming effect of LHRH. Journal of Endocrinology 140 R15-R18.

Mulvaney JM \& Roberson MS 2000 Divergent signaling pathways requiring discrete calcium signals mediate concurrent activation of two mitogen-activated protein kinases by gonadotropin-releasing hormone. Fournal of Biological Chemistry 275 14182-14189.

Mulvaney JM, Zhang T, Fewtrell C \& Roberson MS 1999 Calcium influx through L-type channels is required for selective activation of extracellular signal-regulated kinase by gonadotropin-releasing hormone. Fournal of Biological Chemistry 274 29796-29804.

Naor Z, Harris D \& Shacham S 1998 Mechanism of GnRH receptor signaling: combinatorial cross-talk of $\mathrm{Ca} 2+$ and protein kinase C. Frontiers in Neuroendocrinology 19 1-19.

Pinski J, Lamharzi N, Halmos G, Groot K, Jungwirth A, Vadillo-Buenfil M, Kakar SS \& Schally AV 1996 Chronic administration of the luteinizing hormone-releasing hormone (LHRH) antagonist cetrorelix decreases gonadotrope responsiveness and pituitary LHRH receptor messenger ribonucleic acid levels in rats. Endocrinology 137 3430-3436.

Reiss N, Llevi LN, Shacham S, Harris D, Seger R \& Naor Z 1997 Mechanisms of mitogen-activated protein kinase activation by gonadotropin-releasing hormone in the pituitary $\alpha \mathrm{T} 3-1$ cell line: differential role of calcium and protein kinase G. Endocrinology 138 1673-1682.

Roberson MS, Misra-Press A, Laurance ME, Stork PJ \& Maurer RA 1995 A role for mitogen-activated protein kinase in mediating activation of the glycoprotein hormone alpha-subunit promoter by gonadotropin-releasing hormone. Molecular and Cellular Biology 15 $3531-3539$

Stanislaus D, Janovick JA, Ji T, Wilkie TM, Offermanns S \& Conn PM 1998 Gonadotropin and gonadal steroid release in response to a gonadotropin-releasing hormone agonist in Gqalpha and G11 alpha knockout mice. Endocrinology 139 2710-2717.

Stojilkovic SS, Reinhart J \& Catt KJ 1994 Gonadotropin-releasing hormone receptors: structure and signal transduction pathways. Endocrine Reviewes 15 462-499.

Sundaresan S, Colin IM, Pestell RG \& Jameson JL 1996 Stimulation of mitogen-activated protein kinase by gonadotropin-releasing hormone: evidence for the involvement of protein kinase c. Endocrinology 137 304-311.

Topilko P, Schneider-Maunoury S, Levi G, Trembleau A, Gourdji D, Driancourt MA, Rao CV \& Charnay P 1998 Multiple pituitary and ovarian defects in Krox-24 (NGFI-A, Egr-1)-targeted mice. Molecular Endocrinology 12 107-122.

Weiss J, Cote CR, Jameson JL \& Crowley WF Jr 1995 Homologous desensitization of gonadotropin-releasing hormone $(\mathrm{GnRH})$ stimulated luteinizing hormone secretion in vitro occurs within the 
duration of an endogenous GnRH pulse. Endocrinology 136 138-143.

Wurmbach E, Yuen T, Ebersole BJ \& Sealfon SC 2001

Gonadotropin-releasing hormone receptor-coupled gene network organization. Fournal of Biological Chemistry 276 47195-47201.

Zhang T, Mulvaney JM \& Roberson MS 2001 a Activation of mitogen-activated protein kinase phosphatase 2 by gonadotropin-releasing hormone. Molecular and Cellular Endocrinology $17279-89$.
Zhang T, Wolfe MW \& Roberson MS 2001 $b$ An early growth response protein $(\mathrm{Egr}) 1$ cis-element is required for gonadotropin-releasing hormone-induced mitogen-activated protein kinase phosphatase 2 gene expression. Fournal of Biological Chemistry $27645604-45613$.

Received in final form 20 September 2005 Accepted 10 October 2005 